\title{
DISCURSOS E ESTILOS DE DOCENTES DE FLE E A INFLUÊNCIA DA CULTURA FRANCESA NA FORMAÇÃO DA SOCIEDADE BRASILEIRA ${ }^{1}$
}

\begin{abstract}
Ana Cláudia Barbosa Giraud ${ }^{2}$
RESUMO: Ao longo do Século XX o estatuto da língua francesa como língua estrangeira sofreu mudanças significativas. Dessa maneira, é importante que seja realizada uma reflexão considerando a perda de prestígio da língua francesa no cenário pós-moderno global e suas influências sobre as identidades de docentes de Francês Língua Estrangeira (FLE). Nesse sentido, esse trabalho tem como foco a análise do discurso de docentes de língua francesa de duas instituições de Ensino Superior estando fundamentado sobre os aportes teórico-metodológicos da Análise de Discurso Crítica (ADC), sobretudo, a partir dos estudos de Fairclough (2001, 2003), Chouliaraki \& Fairclough (1999) e Magalhães (2000, 2006). De acordo com essa perspectiva, a linguagem é uma prática social e as estruturas linguísticas se configuram como modos de ação e interação sobre as pessoas e sobre o mundo, de forma que o discurso constitui um espaço de luta hegemônica. A metodologia utilizada nesse estudo compõe um diálogo entre a ADC e a pesquisa qualitativa. Os dados - entrevistas individuais - são examinados em seus aspectos linguísticos e ideológicos focalizando o significado representacional e o significado identificacional dos textos. Os resultados apontam para uma representação da língua e da cultura francesas ligada ao caráter afetivo da relação que esses/essas profissionais com elas mantém.
\end{abstract}

PALAVRAS-CHAVE: Análise de Discurso Crítica, Língua e Cultura Francesas, Globalização.

RÉSUMÉ : Tout au long du XXe siècle le statut de la langue française comme langue étrangère a subit des changements significatifs. Il est donc important qu'une réflexion considérant la perte de prestige de celle-ci sur la scène mondiale post-moderne et ses influences sur les identités des professeurs de Français Langue Étrangère (FLE) soit menée. Dans ce sens, ce travail a pour but l'analyse du discours de professeurs de langue française de deux institutions d'enseignement supérieur. Il est construit sur les fondements théoricométhodologiques de l'Analyse de Discours Critique (ADC), principalement sur les études de Fairclough (2001, 2003), Chouliaraki \& Fairclough (1999) et Magalhães (2000, 2006). D'après cette perspective, le langage est une pratique sociale et les structures linguistiques constituent des manières d'agir et d'interagir sur les gens et sur le monde, du fait que le discours constitue un espace de lutte hégémonique. La méthodologie utilisée dans cette étude compose un dialogue entre l'ADC et la recherche qualitative. Les données - des entretiens individuels - sont examinées dans leurs aspects linguistiques et idéologiques mettant l'accent sur la signification représentationnelle et la signification identificationnelle des textes. Les résultats montrent une représentation de la langue et de la culture françaises liée à la nature affective du rapport que ces professionnels/professionnelles maintiennent avec celles-ci.

MOTS-CLÉS : Analyse de Discours Critique, Langue et Culture Françaises, Mondialisation.

\footnotetext{
${ }^{1}$ Este trabalho foi apresentado parcialmente em um simpósio na Universidade de Campinas e na Universidade de Brasília e integra a tese de doutorado que desenvolvo junto ao Programa de Pós-Graduação em Linguística na Universidade Federal do Ceará, sob a orientação da Professora Doutora Izabel Magalhães.

${ }^{2}$ GIRAUD, Ana Cláudia Barbosa. Mestra em Linguística Aplicada (Universidade Estadual do Ceará) e professora da Casa de Cultura Francesa - UFC. E-mail: cbgiraud@hotmail.com
} 


\section{Introdução}

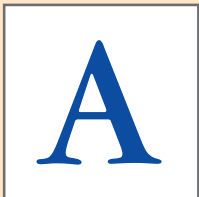

Análise de Discurso Crítica (ADC) pode ser definida como uma abordagem teórico-metodológica transdisciplinar, situando-se em um campo de confluência entre a Linguística e as ciências sociais críticas. Embora existam diferentes abordagens em ADC, é a Teoria Social do Discurso (Abordagem Dialético-Relacional), desenvolvida por Norman Fairclough que nos serve de referência. Sob essa perspectiva, a linguagem é parte irredutível da vida social não podendo ser apreendida sem considerarem-se as práticas sociais, entendidas como "maneiras recorrentes pelas quais agimos e interagimos no mundo" (CHOULIARAKI e FAIRCLOUGH, 1999, p. 21).

Para a ADC, a relação entre linguagem e sociedade é de natureza dialética, de forma que "questões sociais são, em parte, questões de discurso" (idem, p. vii). Por isso desenvolve pesquisas críticas em torno do discurso e da mudança social na sociedade contemporânea. O discurso é um modo de ação historicamente situado, constituído socialmente e produtor de identidades, relações sociais e sistemas de conhecimento e crença. Ele é moldado e molda a estrutura social, de forma que há uma relação dialógica entre discurso e sociedade. Desse modo, ao mesmo tempo em que contribui para sustentar e reproduzir o status quo, o discurso também contribui para transformá-lo, possibilitando uma mudança na vida social. A esse respeito, Fairclough observa:

A prática discursiva é constitutiva tanto de maneira convencional como criativa: contribui para reproduzir a sociedade [...] mas também contribui para transformá-la. Por exemplo, as identidades de professores e alunos e as relações entre elas, que estão no centro de um sistema de educação, dependem da consistência e da durabilidade de padrões de falar no interior e no exterior dessas relações para sua reprodução. Porém, elas estão abertas a transformações que podem organizar-se parcialmente no discurso: na fala da sala de aula, do parquinho, da sala dos professores, do debate educacional, e assim por diante (FAIRCLOUGH, 2001, p. 92). 
De acordo com o linguista britânico, nas práticas sociais cotidianas, o discurso se apresenta de três formas simultâneas e dialéticas. Inicialmente, como parte da atividade social, como ação e interação falada ou escrita, ou seja, como gêneros discursivos. Em seguida, como discursos ou representações, como maneiras particulares de representar. ${ }^{3}$ Por último, o discurso figura como maneiras particulares de ser, como identidades, estilos. Destarte, a ADC investiga a relação do texto com o evento social a que está ligado buscando elucidar em que medida o discurso constrói, mantém ou transforma as práticas sociais.

Gêneros, discursos e estilos são, respectivamente, meios relativamente estáveis e duráveis de agir, representar e identificar. São tidos como elementos de ordens do discurso no nível da prática social. Quando analisamos textos específicos como partes de eventos específicos, estamos realizando duas tarefas interconexas: (a) olhando-os em termos dos três aspectos do significado: Ação, Representação e Identificação e como são realizados nos diferentes aspectos de textos (vocabulário, gramática, etc.); (b) estabelecendo a ligação entre o evento social concreto e a prática social mais abstrata ao perguntar que gêneros, discursos e estilos estão ali delineados, e como os diferentes gêneros, discursos e estilos se articulam juntos no texto (FAIRCLOUGH, 2003, p. 28).

Dialogando com os estudos em Linguística Sistêmico Funcional (LSF) de Michael Halliday, Fairclough - ao longo de seu trabalho - articula as macrofunções de Halliday (função ideacional, função interpessoal e função textual) com os conceitos de gêneros (modos de agir), discursos (modos de representar) e estilos (modos de ser). Do referido diálogo surgem três principais tipos de significados dos textos - o significado acional, o significado representacional e o significado identificacional - que devem ser investigados em uma análise de discurso crítica, uma vez que os modos como agimos, representamos e identificamos discursivamente o mundo e a nós mesmos têm efeitos tanto na tessitura do texto quanto na reprodução ou transformação das práticas sociais. É preciso, contudo, ressaltar que embora esses tipos de significados sejam abordados separadamente para fins analíticos, eles não são discretos, ocorrendo simultânea e dialeticamente e em uma maior ou menor medida (FAIRCLOUGH, 2003).

No contexto do presente estudo, cujo foco são os discursos e estilos de docentes de língua francesa, é importante considerar que apesar de permanecer uma língua hegemônica, a língua francesa tem progressivamente perdido o status de que desfrutou quando ocupava o espaço de língua franca e hoje não ocupa lugar de destaque nos projetos das políticas linguísticas de países não francófonos, como é o caso do Brasil. A globalização tem priorizado o ensino do inglês com vistas ao mercado de bens e serviços. No entanto, não podemos dizer que essa é uma questão puramente econômica que se reflete no campo social, ela passa diretamente pelo discurso. Hegemonias linguísticas internacionais alimentam-se de crenças e atitudes em face de hierarquias linguísticas e

\footnotetext{
${ }^{3} \mathrm{O}$ termo discurso (empregado no singular) diz respeito a um significado mais geral, configurando-se como manifestação da linguagem na prática social, enquanto o termo discursos aponta para um significado mais específico, relativo à representação, a uma determinada visão de mundo, significando uma "maneira particular de representar parte do mundo".
} 
imbricam-se com a designação de mais recursos à língua dominante (PHILLIPSON, 2002). Logo, a problemática contemporânea do estatuto da língua francesa atinge dimensões discursivas e identitárias, na medida em que discursos dominantes inculcam representações que orientam identidades (FAIRCLOUGH, 2003).

Por essa razão, este estudo se inscreve em uma perspectiva crítica dos estudos da linguagem em que esta é apreendida como prática social, de forma que não se pode estudar somente as características linguísticas dos textos, mas também os aspectos extralinguísticos presentes nas relações implicadas nos eventos sociais. De acordo com esse horizonte dos estudos linguísticos contemporâneos, estudar os processos linguísticos pressupõe o exame da relação entre linguagem e sociedade e requer uma abordagem transdisciplinar, já que "uma única disciplina ou área de investigação não pode dar conta de um mundo fluido e globalizado" (MOITA LOPES, 2006, p. 99).

Além dos aportes da ADC são utilizadas abordagens metodológicas da pesquisa qualitativa (FLICK, 2009; ANGROSINO, 2009). Os dados coletados por meio de entrevistas semiestruturadas realizadas com oito docentes (seis mulheres e dois homens) de francês de duas instituições de ensino superior, são examinados em seus aspectos linguísticos e ideológicos.

Serão focalizados os significados representacional e identificacional de excertos dessas entrevistas. O objetivo é examinar: que representações ancoram suas concepções de língua e cultura francesas; de que maneira essas representações contribuem para a construção de suas identidades; e quais identidades são construídas por meio de seus discursos. Para tanto, apresentamos inicialmente um rápido panorama do legado da cultura francesa para a sociedade brasileira, seguido de uma síntese a respeito da globalização e da mudança de estatuto da língua francesa. Na tese que se encontra em andamento, buscamos refletir acerca do modo como esse fenômeno econômico estaria agindo sobre o estatuto da língua francesa e suas possíveis influências sobre as representações e identidades dos/das docentes. Como os dados ainda estão sendo tratados, neste artigo discutiremos somente a natureza da relação que docentes do ensino superior mantêm com a língua/cultura francesas.

\section{O legado da cultura francesa}

Após um longo percurso de consolidação que se iniciou no Século XVI, a língua francesa se constituiu no Séc. XVIII como a língua das elites europeias. Foi nos salões em que as elites financeiras e intelectuais francesas se encontravam que a língua francesa passou a ser referência para todo o continente europeu. Ademais, a expansão colonizadora da França também contribuiu para que sua língua e cultura se tornassem modelo para muitos países do Ocidente ao longo do Séc. XIX (SANTOS, 2001).

A chegada da Corte Real Portuguesa no Rio de Janeiro, em 1807, intensificou a influência francesa sobre nossa cultura, notadamente na literatura, na música, na arquitetura, na política, na moda e na gastronomia. De acordo com Pietraróia (2008) a criação do Colégio Pedro II, em 1837, assinala o início do ensino obrigatório da língua francesa nas escolas secundárias brasileiras. Desse período até o início do século XX, o ensino do francês prolifera em muitas outras instituições do país. A autora destaca que "entre lições de civismo e moral, os alunos eram conduzidos aos textos 
literários franceses, uma vez que ter acesso a esses textos era essencial num mundo em que a França era um referencial literário e cultural" (PIETRARÓIA, 2008, p. 11).

Nesse sentido, Ponte (2010) sublinha que, além do patrimônio cultural, os artigos de luxo, bem como os valores e comportamentos vindos da França, respondiam às expectativas das novas sociedades urbanas modernas. Por essa razão, emergiu nessa época "uma onda de afrancesamento que recobriu as relações sociais nas principais cidades brasileiras, entre o final do século XIX e as primeiras décadas do século XX” (PONTE, 2010, p. 153).

Ressalte-se o papel das missões francesas no Brasil, que vieram com a criação da Universidade de São Paulo, renovando e modernizando os estudos das ciências humanas. Dentre os vários professores franceses que deixaram um legado notável não só para a USP, mas para todo o país, estão Roger Bastide e Claude Lévi-Strauss. Essas missões tiveram um considerável "papel formador na constituição de um pensamento nacional” (FIGUEIREDO \& GLENADEL, 2006, p. 17).

Antônio Cândido destaca a herança do patrimônio cultural francês no Brasil em seu texto Formação da literatura brasileira (1959) chamando a atenção para o fato de que ele não era só visível em literatura, mas também nas artes em geral, nas ciências e no pensamento.

$\mathrm{O}$ autor enfatiza a influência que a língua e a cultura francesas representaram para a civilização brasileira até meados do século XX, quando o francês era quase como uma segunda língua, exercendo "no Brasil o papel formador que as culturas clássicas da Grécia e de Roma exerceram na Europa" (CÂNDIDO, 2005, p. 13). Com a ascensão dos Estados Unidos no cenário global, o estatuto da língua francesa sofreria uma importante transformação, como veremos a seguir.

\section{A globalização e o estatuto da língua francesa}

Sobretudo após a Segunda Guerra Mundial, os Estados Unidos foram paulatinamente assumindo o papel de modelo econômico e cultural que até então fora desempenhado pela França (PONTE, 2010). Em decorrência desse novo modelo americano, a língua francesa perdeu um pouco de sua hegemonia como língua estrangeira. Nesse sentido, Canclini (2010) assinala que em menos de cinquenta anos Paris e outras capitais europeias que eram referências primordiais para o pensamento e para a estética latino-americana perderam seus lugares. São cidades americanas que atualmente povoam nosso imaginário: "Nova York, para as elites culturais; Miami e Los Angeles, para o turismo de classe média; Califórnia, Texas, Nova York e Chicago, para os trabalhadores que emigram" (CANCLINI, 2010, p. 15). Refletindo sobre essa crescente uniformização do modelo cultural norte-americano, que tem na música, no cinema e nas mídias em geral aliados poderosos de divulgação dos padrões culturais e da língua inglesa, Bueno (2006) ressalta:

O inglês é visto como um agente formador de um estilo de vida global homogêneo, em que se tende a criar uma comunidade de consumo mundial, transformando os indivíduos em consumidores indiferenciados e privando-os da qualidade de cidadãos com os seus costumes próprios. (BUENO, 2006, p. 96).

De acordo com Moita Lopes (2008), no ritmo do desenvolvimento global contemporâ- 
neo as projeções são que em dez anos mais de três bilhões de pessoas falem inglês no mundo. Isto significa que a língua inglesa se tornou uma grande fonte de geração de divisas para os Estados Unidos, a Inglaterra e outros países, pontuando a questão da mercantilização do ensino. O linguista afirma que "trata-se, portanto, não somente de uma língua que ajudou e ajuda a construir um império, mas que é, de fato, um império em si mesma” (LOPES, 2008, p. 315).

Preocupado com as consequências ideológicas que esse estado de coisas suscita, em seu último livro, Contre la pensée unique (2012), Claude Hagège advoga "em favor da diversidade das formas de pensar, das culturas e das línguas" (p. 7). O autor denuncia o pensamento único, propagado por meio das ideias neoliberais e da língua inglesa e tacitamente aceito por dirigentes políticos, cientistas, pesquisadores e formadores de opinião, conclamando a todos a resistirem contra o "mimetismo do servilismo e a mediocridade que dele é a consequência inevitável" (HAGËGE, 2012, p. 236) que se difunde atualmente no mundo inteiro.

No caso do Brasil, apesar da acentuada influência da cultura francesa em vários domínios de nossa sociedade e do ensino do francês ainda se manter bastante atuante em determinadas cidades brasileiras, o processo de perda de destaque do ensino de FLE acentuou-se na década de 1960, quando o governo brasileiro baniu o francês do currículo escolar obrigatório e em 1996, com a exclusão da obrigatoriedade da língua francesa na prova de seleção da escola de diplomatas brasileiros, o Instituto Rio Branco (NASCIMENTO, 2006, p. 107). Pode-se também afirmar que a criação do MERCOSUL - e sua consequente ênfase sobre a língua espanhola - e a ausência da língua francesa nas provas do ENEM representaram, de certo modo, um novo prejuízo para o prestígio da língua e a consequente diminuição de perspectivas de vagas no mercado de trabalho para os profissionais do ensino de FLE.

No entanto, apesar de todas essas perdas, o que se percebe na prática é que a língua francesa ainda figura como a segunda língua estrangeira mais procurada nos cursos públicos e particulares de idiomas em Fortaleza e em muitas outras cidades brasileiras, perdendo somente para o inglês ${ }^{4}$. Diferentemente do que se configurou até meados do século XX, o atual interesse pelo francês é menos impulsionado por crenças ou pela tradição cultural que por interesses acadêmicos e comerciais, como observa Moreira (2006):

O francês agora não é mais apenas uma língua de cultura, nos moldes de uma cultura de grandes obras, grandes escritores etc.; ele é também uma língua de negócios. No âmbito internacional, a ampliação e fortalecimento da União Europeia e a valorização do "euro" vêm juntar-se aos fatores de expansão da língua e cultura francesas. No Brasil, com a instalação de empresas francesas aqui no Paraná [e em outras cidades brasileiras], como a construtora de automóveis Renault e com a ampliação do comércio exterior ocorre o aumento de intercâmbios e convênios com universidades. Um novo perfil da língua e cultura francesas passa então a ser delineado no âmbito profissional e acadêmico. (MOREIRA, 2006, p. 2).

\footnotetext{
${ }^{4}$ Esses dados não são oficiais, mas fruto de observação pessoal ao longo dos treze anos de experiência no ensino de FLE em várias escolas particulares em Fortaleza, bem como de conversas com profissionais de outras instituições particulares e públicas na capital cearense. Eles também são confirmados pelos trabalhos de Moreira (2006) e Vergueiro (2009).
} 
Ao lado das escolas de idiomas, muitas universidades ainda resistem oferecendo anualmente à comunidade vagas nos Cursos de Letras Francês. Entretanto, devido ao estatuto atual da língua francesa e ao número reduzido de vagas no mercado de trabalho para os profissionais do ensino de francês, a procura por esses cursos tem sido, de uma forma geral, menos expressiva.

É em meio à discussão sobre essas mudanças que se situa o estudo sobre os discursos e estilos de docentes de língua francesa. Interessa-nos particularmente discutir qual a natureza da relação que professores e professoras de língua francesa do ensino superior mantêm com a língua e a cultura francesas, de acordo com a análise do significado representacional (discursos) e do significado identificacional (estilos) dos textos selecionados. Relativamente à questão da interpretação textual, Magalhães (2002) pontua:

As formas que entram na composição de um texto derivam seu significado de práticas discursivas passadas, um significado que foi cristalizado em convenções discursivas. Portanto, o significado potencial de um texto é heterogêneo, já que se trata de um conjunto de significados diversos e até mesmo contraditórios, imprimindo ambivalência ao texto. Cabe aos leitores a opção pela atribuição de um significado e de uma interpretação particular. (MAGALHÃES, 2002, p. 85).

Uma vez que se trata de uma pesquisa de natureza qualitativa a reflexão de Magalhães (2002) guiará todo o processo de análise em que buscaremos averiguar que crenças e/ou ideologias estão associadas às concepções de língua francesa e de que forma elas contribuem para a constituição das identidades dos/das docentes.

\section{Modos de representar e modos de ser: o encantamento pelo francês}

O grupo participante da pesquisa é composto por oito docentes do ensino superior, dos quais seis são mulheres e dois são homens. Pode-se dizer que esses números refletem uma realidade da categoria, que é formada por uma maioria representativa de mulheres. A representatividade da amostra não se fundamenta em critérios estatísticos, mas no fato do grupo de docentes ser capaz de representar a relevância do fenômeno estudado "em termos de experiência e envolvimento dos participantes com esses fenômenos" (FLICK, 2009, p. 47). Seis docentes pertencem ao quadro efetivo de suas instituições de ensino e dois ao quadro temporário. A faixa etária do grupo varia de 32 a 63 anos. Todos/todas têm graduação em Letras-Francês, fizeram estudos de pós-graduação e trabalham há pelo menos dois anos em suas respectivas instituições. Os/as profissionais serão identificados por meio de nomes fictícios para garantir sua privacidade.

Os excertos aqui analisados constituem relatos dos/das participantes coletados por meio de entrevista individual. As entrevistas se basearam em perguntas direcionadas no sentido de responderem a objetivos preestabelecidos, em acordo com a definição de Angrosino (2009), para quem "entrevistar é um processo que consiste em dirigir a conversação de forma a colher informações relevantes" (ANGROSINO, 2009, p. 61). Os textos selecionados correspondem às respostas à questão Como e quando surgiu o seu interesse pela língua francesa? A questão foi formulada com o intuito 
de averiguar o modo como os/as participantes representam e se identificam com a língua e a cultura francesas, suas perspectivas particulares de representação do mundo e os traços linguísticos peculiares a seus discursos.

Como vimos, o significado representacional está relacionado ao conceito de discurso como modos particulares de representação. Logo, diferentes discursos constituem perspectivas distintas de mundo, associadas às diferentes relações que as pessoas mantêm com ele. Nesse sentido, a análise não pode deixar de levar em conta as maneiras distintas as quais diferentes aspectos do mundo são lexicalizados no texto, pois a escolha dos modos de representação depende dos interesses particulares e das práticas/posições enfatizadas na representação" (RAMALHO; RESENDE, 2011, p. 142).

O significado identificacional está relacionado ao conceito de estilo como formas de ser, isto é, ao aspecto discursivo de identidades. Fairclough pontua que estilos constituem o aspecto discursivo das formas de ser, identidades. Quem você é, é em parte uma questão de como você fala, como você escreve, como também uma questão de expressão corporal - como você olha, a forma de parar, como se move e assim por diante (FAIRCLOUGH, 2003, p. 159).

As categorias analíticas pertencentes ao enquadre teórico-metodológico da ADC que servirão de base para a análise serão metáfora, identificação relacional e interdiscursividade.

Albert

Como e quando surgiu seu interesse pela língua francesa?

Surgiu quando eu era menino. Uns dez pra onze anos. Meu pai, ele era francófono, meu avô por sua vez, pai dele, já estudava francês. Papai girava a manivela do gramofone lá em Cascavel pra eu estudar. E aí quando eu fiz a antiga quinta série do ginásio, tinha uma aula de francês e eu me encantei. [...] Em 84 eu entrei na faculdade, com 17 anos, mas eu já era fluente. Era uma paixão.

\section{Cristina}

Ah, surgiu há muito tempo atrás quando eu ainda era da sétima série. Eu tive uma professora chamada Alice que foi minha primeira professora de língua estrangeira, no caso foi o francês. Nunca tinha estudado língua estrangeira e comecei pelo francês... Aí eu me apaixonei pelo francês, pela maneira que ela ensinava. Era aquele livro Le Français et lavie, (risos) acho que é chamado de Manger rouge. Então eu logo descobri que eu tinha dom pra ensinar francês, assim, que eu tinha dom para aquela língua porque eu ajudava os meus colegas [...] Então eu era uma espécie de monitora voluntária na sétima série.

\section{João Paulo}

... quando eu estudava no antigo ginásio [...] eu estudei dois anos de francês e os outros dois anos do Ginásio, inglês. Eu só fui estudar francês novamente quando eu morava em São Luis. [...] Normalmente, quem estuda francês, e isso eu tenho perguntado a muitas pessoas, é porque realmente GOSTA DA LÍNGUA. [...] É por amor! Já o inglês, não. O inglês foi por necessidade, apesar de que eu gosto 
muito de inglês, mas o inglês é mais por necessidade, não é?

Geórgia

Eu tenho uma irmã que era uma menina, que é uma senhora muito estudiosa hoje [...] ela era tão excelente aluna que a Aliança Francesa ofertou algumas vagas para os melhores alunos e minha irmã tava incluída. E ela ia pra Aliança Francesa e me levava [...] Então aquilo ali me encantou [...] Aí então o que é que eu faço na hora de escolher minha, minha profissão? Eu fiz o curso clássico que eram línguas e tinha francês, e eu me apaixonei tanto pela língua que era uma das melhores alunas, que eu decidi fazer letras e quando fiz letras peguei FrancêsPortuguês, sempre com mais “accent”, com mais vontade pelo francês.

Margarida

Desde pequena mesmo, desde menina eu não sabia exatamente o que que eu seria na vida adulta como profissional, mas sempre tive um encantamento por francês. Eu pequena, seis sete anos, né, muito ligada a uma tia, irmã da minha mãe [...] eu tenho assim lembrança dessa minha tia a quem eu era muito ligada e já era professora de francês e tal, ela passou uns dois anos da França e quando ela voltou, eu tinha o que, tinha uns oito anos, né? Então minha avó fez um poeminha em francês, né? [...] À notre tante chérie / À son retour de Paris/Nous t'embrassons tendrement / Avec des baisers et des sourires. Pronto. Foi feito pela minha avó, minha avó que fez. Mas olhe, parece que eu to me vendo no terraço da casa da minha avó.

\section{Mariana}

Eu acho que era o destino que quis que eu estudasse francês porque nunca foi opção minha estudar francês. Na verdade eu sempre quis ser, ter outra profissão e eu lembro que, eu acho que quando eu tinha 14,13 pra 14 anos, eu fiz a seleção pra estudar no I... para inglês e eu não consegui atingir o perfil para a turma que eu tinha feito a inscrição [...] Como eu era classificável, eu tinha direito, eu tinha pontuação - eu tinha atingido a pontuação, mas não para a turma do inglês - então eu poderia escolher uma segunda língua. Então dentro de todas as... as segundas opções que eu tinha a meu dispor eu escolhi o francês, porque eu lembro que na época a minha irmã estudava francês. Então o fato de ver a minha irmã estar estudando francês, de uma certa forma me atraiu.

\section{Natália}

Eu fiz francês no C..., que na época era Escola técnica e decidi que queria continuar meus estudos de francês de uma forma mais aprofundada, não só fazendo um curso pra me comunicar. [...] Então eu decidi fazer letras, bem assim por intuito, né? E foi aqui no curso de letras que eu descobri que eu queria ser professora de francês, né ? Assistindo as aulas das minhas professoras queridas. Já era Letras-Francês. No vestibular a gente não precisava optar, né? A gente optava já quando tava aqui dentro do curso. Sim, então assistia as aulas de francês, eram as minhas aulas favoritas, adorava, e aí fui fazer a Cultura Francesa e tudo que apa- 
recia na área de francês, relacionado com o francês eu fazia, porque justamente era... me encantava, né?

\section{Simone}

Aí é uma história familiar. Bem familiar. Que talvez o Bourdieu te ajude a entender isso, aquela coisa de captar o familiar de um determinado habitus. Minha mãe, como sua irmã, na época em que eram jovens estudaram francês. [...] Aí daí da minha parte, quando eu tinha a idade que ela tinha quando talvez começou na A..., ela me botou na A... Eu tinha 13 anos. [...] Tinha preguiça, mas minha mãe tava sempre muito por perto, dizendo que eu não desistisse e acabei tomando gosto. Não me lembro quando, mas comecei a tomar gosto.

Examinando os aspectos semânticos dos textos, a análise preliminar dos dados revela o caráter afetivo da relação que os/as docentes mantêm com a língua e cultura francesas, relações as quais em alguns casos remontam a infância, como no caso de Margarida (Desde pequena mesmo, desde menina eu não sabia exatamente o que que eu seria na vida adulta como profissional, mas sempre tive um encantamento por francês. Eu pequena, seis sete anos, né?).

Esse caráter afetivo pode ser observado, sobretudo, por meio do exame do léxico utilizado pelos/pelas docentes e de seus padrões de ocorrência, a exemplo do substantivo "encantamento", empregado por Margarida e de outros termos que apontam para o mesmo sentido. Os verbos "encantar" (E tudo que aparecia na área de francês, relacionado com o francês eu faz̧ia, porque justamente era... me encantava, né? Natália), "atrair" (Então o fato de ver a minha irmã estudando francês, de uma certa forma, me atraiu. Mariana), "se apaixonar" (E eu me apaixonei pelo francês, pela maneira que ela ensinava. Cristina) e "gostar" (Normalmente, quem estuda francês é porque gosta. João Paulo). Da mesma forma os substantivos "amor" (É por amor! João Paulo), "gosto" (Não me lembro quando, mas comecei a tomar gosto. Simone) e "vontade" (quando fiz letras peguei Francês-Português, sempre com mais "accent", com mais vontade pelo francês. Georgia).

De acordo com Fairclough (2003) a análise das metáforas presentes em um texto pode evocar as representações de mundo do enunciador. Ao selecionar uma determinada metáfora este termina por realçar ou encobrir certos aspectos do mundo, indicando ainda de que forma essas representações contribuem para a construção de sua identidade. Os termos metafóricos empregados pelos/pelas docentes, evocam em menor ou maior grau, uma relação emotiva, passional dos/das docentes com a língua francesa, que é, dessa forma, personificada, de modo que parecem ter sucumbido aos encantos de uma entidade envolvente e sedutora que os fascina e os inflama e que faz parte de seu imaginário representativo, de suas perspectivas de mundo e das relações que mantêm com o mundo e com outras pessoas.

Além da presença de metáforas, os dados apontam para a necessidade de abordagem da categoria analítica identificação relacional, que tem o objetivo de identificar atores sociais em termos das relações pessoais, de parentesco ou de trabalho que têm entre si. As questões a serem examinadas devem contemplar a forma como atores sociais são identificados nos textos, que relações eles mantêm com o enunciador e que identidades são construídas por meio de seus discursos (RAMALHO; RESENDE, 2010). 
Nesse sentido, no que diz respeito às relações sociais dos/das docentes, é interessante observar que em todos os depoimentos há uma referência a alguém que foi o responsável pelo seu ingresso no francês e pelo seu consequente "encantamento": a(s) professora(s) (Cristina e Natália); a irmã (Geórgia e Mariana); a mãe (Simone); o pai (Alberto) ou a tia (Margarida). As relações que as participantes mantêm com os referidos atores sociais é uma relação de admiração que aponta novamente para a questão do afeto. A categoria das ordens de discurso (ou interdiscursividade) - ligada aos modos de representar aspectos do mundo em textos - pode revelar que discursos se encontram ali articulados e como estão articulados (Fairclough, 2003). De acordo com essa perspectiva, não podemos esquecer a importância e a influência que o patrimônio cultural francês teve na formação da cultura brasileira, como já foi aqui destacado.

Nesse nível da análise, pode-se dizer que os discursos dos/das participantes da pesquisa estão arraigados em representações que circulam nas práticas sociais sobre a língua francesa, veiculando uma perspectiva de mundo ligada ao glamour, ao poder de uma língua que por muito tempo esteve (e de certa forma até hoje está) ligada às elites - intelectuais, acadêmicas, artísticas e financeiras - e à sua beleza e sedução evocadas pela sonoridade de seu sistema fonológico. Assim, não seria incorreto afirmar que os/as entrevistado(a)s protagonizam um processo de encantamento e paixão que faz parte do apelo ideológico colonizador europeu em seus ritos de garantia de superioridade estética, filosófica, acadêmica e artística, sobre as mentes de sociedades dominadas.

O francês se estabelece em seu poder simbólico atraindo jovens a esse mundo de ascensão cultural. Ser um professor de Francês é uma conquista, uma travessia em busca de um status que ainda não se desfez do imaginário coletivo, apesar da globalização e da consequente diminuição da hegemonia do francês como língua estrangeira. O encantamento está ligado a todas as concepções de grandeza atreladas às práticas discursivas que se concretizaram no período em que a França e seu patrimônio cultural ainda eram uma grande referência mundial. O "encantamento", "a paixão" evocam as representações mentais do discurso da superioridade da cultura francesa. Evocam também, de certa forma, a matriz gerativa das ideologias colonialistas, assimiladas por colonizados, dissimuladas pelo toque suave do charme, do glamour, da beleza, foco de resistência das elites dominantes, cercadas ainda de ornamentos simbólicos presentes na sociedade brasileira, das décadas de formação educacional dos/das protagonistas da pesquisa.

Assim, dos dados emergem toda a carga cultural (grandeza histórica, intelectual, política, econômica, linguística, etc.) que se deposita na mente e no coração dos/das participantes, mas também da autora desta pesquisa e de certa forma, de um modo geral, de todos os/as docentes de língua francesa. No entanto, como vimos, essa grandeza cultural parece não mais constituir o exclusivo motivo do interesse pela língua francesa no mundo globalizado contemporâneo. Podemos afirmar que mais do que por essa empatia, os jovens que ocupam atualmente as salas de aula das universidades brasileiras são movidos por questões ligadas às novas configurações sociais, à mobilidade estudantil internacional e às demandas do mercado de trabalho que vão além do âmbito do ensino e criam novos campos de atuação.

Para finalizar é importante levar em consideração que a reflexão aqui apresentada fundamentou-se sobre um recorte em meio a um contingente muito maior de dados que estão sendo analisados em seu conjunto na tese de doutorado em desenvolvimento. Do mesmo modo, deve-se 
considerar seu caráter de analise qualitativa resultando em uma interpretação pessoal que, embora apoiada em categorias de análise definidas as quais oferecem bases coerentes para a reflexão, não está completa nem constitui uma verdade absoluta.

\section{REFERÊNCIAS BIBLIOGRÁFICAS:}

ANGROSINO, M. Etnografia e observação participante. Trad. de José Fonseca. Porto Alegre: Artmed, 2009.

BUENO, E. U. "O francês e a diferença: em busca de um novo modelo de globalização". In. FIGUEIREDO \& GLENADEL. O francês e a diferença. Rio de Janeiro: 7Letras, 2006. p. 93-100.

CÂNDIDO, A. "Prólogo". In. MARTINS, C. B. (Org). Dialogues entre le Brésil et la France: formation et coopération académique. Recife: Ed. Massangana, 2005. p. 13-6.

Formação da literatura brasileira: momentos decisivos. São Paulo: Martins, 1962.

CANCLINI, N. G. Consumidores e cidadãos. Conflitos multiculturais da globalização. Trad. Maurício Santana Dias. Rio de Janeiro: Editora UFRJ, 2010. 8a Edição.

CHOULIARAKI L. e FAIRCLOUGH, N. Discourse in late modernity. Rethinking Critical Discourse Analysis. Edinburgh: Edinburgh University Presse, 1999.

FAIRCLOUGH, N. Discurso e mudança social. Brasília: Universidade de Brasília, 2001.

Analysing Discourse. Textual analysis for social research. London: Routledge, 2003.

FIGUEIREDO, E.; GLENADEL, P. “O estatuto do francês no mundo de hoje: a diferença 'por vir””. In. FIGUEIREDO \& GLENADEL. O francês e a diferença. Rio de Janeiro: 7Letras, 2006. p. $11-26$.

FLICK, U. Desenho da pesquisa qualitativa. Trad. Roberto Cataldo Costa. Coleção Pesquisa Qualitativa. Porto Alegre: Artmed, 2009.

HAGÈGE, C. Contre la pensée unique. Paris: Éditions Odile Jacob, 2012

MAGALHÃES, I. Teoria crítica de discurso e texto. In. Linguagem em (Dis)curso. V. 4. Tubarão: 2006, p. 113-131.

Eu e tu: a constituição do sujeito no discurso médico. Brasília: Thesaurus, 2000.

MOITA LOPES, L. P. da. "Inglês e globalização em uma epistemologia de fronteira: ideologia linguística para tempos híbridos”. Revista D.E.L.T.A., v. 24:2, p. 309-40, 2008.

A imprescindibilidade de uma linguística aplicada híbrida ou mestiça. Por uma linguística aplicada indisciplinar. São Paulo: Parábola, 2006. p. 86-107.

MOREIRA, J. C. A Representação estereotipada da língua e cultura francesas no discurso dos alunos do Centro de Linguas da UFPR. 2006. Dissertação apresentada ao Programa de Pós-Graduação em Letras da Universidade Federal do Paraná, Curitiba.

NASCIMENTO, R. A. do. "O francês e a diferença: respeito à diversidade cultural”. In FIGUEIREDO \& GLENADEL. O francês e a diferença. Rio de Janeiro: 7Letras, 2006. p. 101-10.

PIETRARÓIA, C. C. "A importância da língua francesa no Brasil: marcas e marcos dos primeiros períodos de ensino”. Revista Estudos Linguísticos. São Paulo, v. 37 (2), pp7-16, 2008.

PHILLIPSON, R. "Línguas internacionais e direitos humanos internacionais". In Esperanto-Doku- 
mentoj, $\mathrm{n}^{\circ}$ 37. 2002. Disponível em http://uea.org/info/portugale/ED37-portugala.html. Consultado em 25.10.2011

PONTE, S. R. Fortaleza belle époque: reforma urbana e controle social. 1860-1930. Fortaleza: Fundação Demócrito Rocha, 2010. 4 ed.

RAMALHO, V. \& RESENDE, V. de M. Análise de discurso (para a) crítica: o texto como material de pesquisa. Coleção Linguagem e Sociedade. Campinas: Pontes Editores, 2011. Vol. 1.

SANTOS, P. C. Petrópolis: história de uma cidade imperial. Petrópolis: Sermograf, 2001. 1. ed.

VERGUEIRO, T. O. de N. Professores de francês apesar de tudo: o papel das representaçöes sociais nessa história de persistência. 2009. Dissertação de Mestrado apresentada ao Programa de Pós-Graduação em Letras da Universidade Federal do Rio Grande do Sul, Porto Alegre. 